\title{
Novel approaches in treatment of Acne vulgaris: Patents related to micro/nanoparticulated carrier systems
}

\author{
Nadica Sibinovska ${ }^{1}$, Venera Komoni ${ }^{1}$, Katerina Ancevska Netkovska ${ }^{1}$, Edina Vranic ${ }^{2}$, \\ Maja Simonoska Crcarevska ${ }^{1}$, Marija Glavas Dodov ${ }^{1 *}$
}

\author{
${ }^{1}$ Faculty of Pharmacy, University "Ss Cyril and Methodius", Majka Tereza 47, 1000 Skopje, Macedonia \\ ${ }^{2}$ Department of Pharmaceutical Technology, Faculty of Pharmacy, University of Sarajevo, \\ Zmaja od Bosne 8, 71000 Sarajevo,Bosnia and Herzegovina
}

Received: August 2016; Accepted: October 2016

\begin{abstract}
Acne vulgaris (acne) is chronic inflammatory dermatosis which affects the pilosebaceous unit, with a varied clinical picture including inflammatory and non-inflammatory cutaneous lessions. This multifactorial disease mostly occurs in adolescents; however, it can also affect children and adults. Different therapy options for acne treatment exist, comprising topical, systemic and hormonal agents or a combination thereof. The choice of the therapy depends on various factors, for instance the severity and extent of the disease and site of involvement. Commonly used topical acne therapies include benzoyl peroxide, salicylic acid, antibiotics, retinoids, azelaic acid, sulfone agents and their combinations. Systemic antibiotics are indicated for use in moderate to severe inflammatory acne and should be used in combination with a topical retinoid and benzoyl peroxide.

The available conventional formulations often cause side effects such as skin irritation, dryness, peeling, itching, leading to reduced patient compliance and compromised therapeutical efficacy. Novel drug delivery systems are promising option for improved acne treatment outcome, as they can diminish the side effects caused by the therapeutic agents or can modulate their properties and at the same time offering possibilities for modified release and improved skin penetration of the active substances.

The cosmetics manufacturers implement micro/nanotechnology in their formulations, while patent protection for cosmetics has gained more importance over the past decades.

This review focuses on micro/nanoparticulated carrier systems that can be used for acne treatment and the published patents concerning them.
\end{abstract}

Keywords: microparticulate systems, nanoparticulate systems, Acne vulgaris, patents

\section{Introduction}

Acne vulgaris (acne) is a chronic inflammatory disease of pilosebaceous unit affecting seborrhoeic areas (mainly face, chest, back), characterized by the presence of comedones, papular and pustular eruptions, purulent cysts and scars (Bergler-Czop, 2014). Although it most often affects

\footnotetext{
*magl@ff.ukim.edu.mk
}

adolescents, acne vulgaris is not uncommon in adults and can be also seen in children (De Medeiros-Ribeiro et al., 2015; Goulden et al., 1997).

The current concept is that the pathogenesis of acne encompasses the interaction of several different pathogenic factors, namely follicular hyperkeratinization, hormonally determined overproduction of sebum and changes in microbial flora in addition to immunological factors and inflammatory processes (Degitz et al., 2007; De Medeiros- 
Ribeiro et al., 2015). Increased sebum production and follicular hyperkeratosis result in the development of microcomedones, while changes in follicular milieu cause the intensive growth of Propionibacterium acnes ( $P$. acnes) (Knor, 2005). In the emergence of acne, other factors such as androgens, Peroxisome proliferator-activated receptor (PPAR) ligands, insulin like growth factor-1 (IGF-1) signaling pathway, regulating neuropeptides and environmental factors are probably involved, which interrupt the natural cycling process in the sebaceous gland follicle and support the transition of microcomedones to comedones and inflammatory lesions (Zouboulis, 2014).

Despite acne not being a life-threatening disease, it has significant physical and psychological consequences such as permanent scarring, reduced self-esteem, social inhibition, depression, anxiety and suicidal tendency (Date et al., 2006). Since it can negatively affect the patients` quality of life, early and aggressive therapy is crucial, with successful treatment promoting much more than just cosmetic benefits (Ramos-e-Silva and Carneiro, 2009). Up to date, various clinical guidelines for management of acne have been proposed. Different factors, such as age of the patient, site of involvement, extent and severity of disease and patient preference may influence the choice of the therapy. A stepwise approach to acne management involves topical agents for mild to moderate acne (topical retinoid as mainstay and/or topical antibiotics) and escalation to oral agents for more resistant cases (oral antibiotics or hormonal agents in conjunction with a topical retinoid or oral isotretinoin alone for severe acne) (Das and Reynolds, 2014).

In spite of various treatments for acne being available, many patients fail to respond adequately and often, the efficacy of the treatments is compromised (Vyas et al., 2014). The active substances and the conventional formulations for local acne treatment have numerous drawbacks, in terms of physico-chemical properties of the active ingredient, stability and limited possibility for penetration into the skin appendages. Numerous side-effects, such as skin irritation, redness, dryness, severe desquamation and photosensitivity occur due to the incapacity for targeted drug delivery to the pilosebaceous units and achievement of optimal concentration at the site of action. These side-effects diminish the patients' compliance (Taglietti et al., 2008; Vyas et al., 2014). Hence, the patients are in search of topical products for skin use that are not only safe and efficient, but are also cosmetically acceptable and easy to use (Taglietti et al., 2008).

Novel delivery strategies for existing drugs and their modifications represent the recent changes in acne treatment, in addition to the development of new medications that target regulatory pathways involved in acne pathophysiology (Moradi Tuchayi et al., 2015). These novel drug delivery systems might minimize the problems associated with the conventional products in terms of penetration, retention, sustained release and therapeutic efficacy.

The micro/nanoparticulated systems have been widely researched both as carriers of active substances and as delivery systems for the cosmetic active ingredients. Encapsulating the active ingredient within these systems is anticipated to result in its protection, release of smaller doses in a continuous period, as well as targeting the pilosebaceous unit that would help achieve an efficient, relatively high local concentration at the site of action (Date et al., 2006). Beside controlled release of the encapsulated drug at the site of action, among the other main advantages of these carrier systems are: an improved stability of the active substance (e.g. active substances sensitive to oxidation, hydrolysis, thermal degradation), possibility for incorporation of incompatible substances, possibility for modification of the physicochemical and the organoleptic properties of the active substance, improved penetration (due to the defined size, structure, surface properties), improved skin tolerance, reduction of side-effects and satisfying aesthetic look of the product (Brenner, 2013; Rosen, 2005). Hence, these novel drug delivery systems are an innovative approach in the dermatological acne treatment and are expected to achieve a greater therapeutic efficacy with a possibility for a so-called size-dependent localization (especially in the hair follicle) and a possibility for diminution of the side-effects of the active ingredient, which makes them superior in comparison with the conventional preparations.

Patent protection has become more important to cosmetics companies over the last 30 years (Union for Ethical BioTrade, 2010). A patent is an exclusive right to use, sell, or import an invention over a limited period of time (20 years from filing) within the country where the application is made. Patents are granted for inventions which are novel, inventive (non-obvious) and have an industrial application (useful). There are other types of exclusive rights from intellectual property rights, but patents provide a broader protection that extends beyond the specific expression of an invention to the invention itself. Due to this control over the technology, the patent holder is in a position to set a higher-than-competitive price for the corresponding good or service, which allows recovery of innovation costs (OECD, 2004). According to the World Trade Organization (WTO)'s Agreement on Trade Related Aspects of Intellectual Property Rights (TRIPS), patents must be available in WTO member states for any invention, in all fields of technology with available protection of minimum of twenty years. TRIPS introduced intellectual property rules into the multilateral trading system for the first time, in an attempt to guarantee the same minimum standards of protection across countries (OECD, 2004).

Intellectual property is rapidly becoming a central element in discussions of business strategy, including cosmetic industry. This trend may not be surprising; the rising importance of intangible capital in industrialized economies is apparent in many statistics. The number of patent applications is growing at double-digit rates in the major patent offices. Licensing and cross-licensing are being employed with greater frequency than ever, particularly so in high- 
technology industries (Harhoff and Hall, 2002).

Nowadays, almost all the larger producers of the cosmetic preparations use micro/nanotechnology in their formulas and most of them have been patented. In 2009, the cosmetics industry accounted for $10 \%$ of all the patents granted in the EU (Colipa, The European Cosmetics Association, 2010). An enormous increase of the number of cosmetic patents has been seen in that last two decades, with the majority of the published patents coming from USA, Japan, Germany and France, while the greatest growth of published patents being seen in China, Japan and Germany. The review of the Scopus database with a keyword acne treatment resulted in 34.489 documented scientific articles and 3855 patents, published from 1855-2015; 180 documented scientific articles and 5 patents were the results of the search of this database with the keywords drug ingredients + acne, published from 1975-2015. The search in the Scopus database with the keywords - microparticles + acne treatment resulted in 6 documented scientific articles and 1 patent, published from 2005-2015. The search within this database with a keyword - nanoparticles resulted in 288.042 scientific articles and 24.726 patents, published from 1978-2015.

In order to get a more realistic image about research in the field of dermatology and nanotechnology, when searching the keywords - nanoparticles + skin, we discovered a list of 2981 scientific articles and 241 patents, published in a period of 1991-2015. It is important to note that, when it comes to nanoparticles for acne treatment, the results are concentrated in 55 scientific articles and 9 patents, published between 2005-2015.

On the basis of the comprehensive results from researching the Scopus database, one can conclude that research in the field of nanotechnology is immense and dates back in the 1990s; only $1 \%$ of it is connected to nanotechnology application on the skin, whereas $0.03 \%$ is research regarding published work for nanoparticles in acne treatment.

This review focuses on the so-far investigated contemporary carrier systems that are being used for acne treatment in terms of formulation and assessment of their efficacy and safety as well as the published patents concerning these systems.

\section{Liposomes}

Liposomes are the first generation of carrier systems of active ingredients that have been widely applied in dermatology and cosmetology (Rosen, 2005). These vesicular systems ranging $15 \mathrm{~nm}$ to $3.5 \mu \mathrm{m}$ in size may incorporate both hydrophilic and lipophilic active substances (Date et al., 2006).

Selection of the phospholipid for preparation of liposomes affects their penetrability, dissolution rate and their effect. Due to the high concentration of linoleic acid, the soy bean phospholipids show significant effects in improv- ing the barrier function of the skin and a remarkable hydration (Egbaria and Weiner, 1990). The liposomes composed of phospholipids with unsaturated fatty acids show higher skin permeation property than the liposomes with saturated (hydrogenated) fatty acids (Zakir et al., 2010). Due to the better penetrative properties, formulations of phospholipids with unsaturated fatty acids, such as unsaturated phosphatidylcholine are adequate carriers for vitamins, provitamins and other substances that improve the regenerative processes in the skin or are efficient as anti-age and anti-acne products (Paye et al., 2005).

The size of these systems also plays an important role for their penetration into the different skin layers. The penetration of liposomes through stratum corneum is decreased as the diameter increases. Therefore, the desired structures of these systems are the so-called LUV (large unilamellar vesicles) composed of one phospholipid bilayer, having a diameter of 50-500 nm (Leeuw et al., 2009). Research has shown that liposomes with particle size up to $600 \mathrm{~nm}$ may penetrate the skin and can be designed in order to deliver the active substance into the skin layers. Unlike them, those having a diameter larger than $1.0 \mu \mathrm{m}$, the so-called non-penetrating liposomes, are designed to maintain themselves on the surface of the skin and provide modified release of the active substances (Schramlová et al., 1997).

Regarding the efficacy in acne treatment, it would be ideal if the active substance is delivered in the hair follicle and the sebaceous unit. Toll et al. (2004) have examined the penetrability of the fluorescently marked particles of various sizes (from 750 to $6000 \mathrm{~nm}$ ) in the hair follicle and have determined that the optimal size would be the one from $300-600 \mathrm{~nm}$, which corresponds to the size of the hair cuticle (Toll et al., 2004).

The liposomes offer a range of advantages when used as carriers for topical delivery of anti-acne drugs. By encapsulation of the active substances, they help in improving their solid-state stability; diminish the occurrence of adverse effects such as skin irritation linked with the use of topical agents for acne treatment, by means of incorporating them in the lipid bilayer or the aqueous core; the phospholipids in their composition may serve as penetration enchancers and facilitate the dermal drug delivery leading to higher drug localization in the skin with concomitant reduction of systemic absorption. The frequency of administration of the active substances used in the treatment of acne can be reduced since the liposomes may serve as local depot, enabling sustained release of dermatological active substances (Date et al., 2006).

The stability issue of the liposomal formulations is one of the major disadvantages of these systems. The instability of the liposomal bilayers leads to leakage of the entrapped material, whereas the oxidation of cholesterol and phospholipids also leads to formulation instability (Vyas et al., 2014). 


\section{Liposomal formulations of retinoids}

All trans-retinoic acid (tretinoin) is used topically in concentrations of $0.025-0.1 \%$ in the form of cream, gel, solution or lotion for the treatment of acne. The occurrence of side-effects such as local irritation, erythema, dryness and skin peeling is noticed when these conventional preparations containing retinoids are used. Studies have shown that the encapsulation of tretinoin in liposomes can decrease skin irritation and at the same time the desired efficacy could be achieved with smaller doses of the active substance (Lamprecht, 2009). The efficacy of tretinoin encapsulated in liposomes has been clinically tested and confirmed. In a double-blind study, the efficacy and appearance of side-effects was comparatively followed in 20 patients with a moderate form of acne that were treated with a liposome gel containing $0.01 \%$ of tretinoin and commercial gel with concentration of $0.025 \%$ or $0.5 \%$ of tretinoin for a period of 10 weeks. The results showed that the encapsulation of tretinoin into the liposome vesicles helped the same efficacy as $0.5 \%$ commercial gel to be achieved, but significantly better tolerance was remarked (Schäfer-Korting et al., 1994).

When incorporated in liposomes, tretinoin shows comedolytic activity five to ten times higher compared to the conventional preparations, and also has a better local tolerability (Brisaert et al., 2001). In a study of MalaekehNikouei et al. (2011), tretinoin, clindamycin and their combination were incorporated in liposomes. Characterization and skin penetration studies of these formulations were carried out and the skin permeation of conventional cream containing tretinoin, clindamycin gel, liposomes with tretinoin and liposomes containing the combination of tretinoin and clindamycin was compared. It was shown that there is a significantly greater retention of tretinoin on the skin surface, when incorporated in liposomes. On the other hand, the retention of clindamycin incorporated in liposomes was higher than the clindamycin gel and the penetration of this active substance was lower for the liposomal formulation (Malaekeh-Nikouei et al., 2011).

Benzoyl peroxide is an efficient active agent in acne treatment, most of all, due to the keratolytic and antibacterial effect, the latter being confirmed in a study by Fluhr et al. (1999), in which a significant antibacterial effect in the infundibula for P. acnes and Micrococcaceae could be demonstrated for a benzoyl peroxide liposomal formulation (Fluhr et al., 1999). The local application of benzoyl peroxide, however, has been followed by severe irritation, redness and dry skin, which limit its acceptance among the patients. One possibility for overcoming the side-effects of using benzoyl peroxide in acne treatment is to incorporate this active substance in liposomes. Namely, in a study by Patel V.B. et al. (2001), it was shown that a gel formulation containing liposomal benzoyl peroxide has improved clinical efficacy in the treatment of acne and reduces the local irritation to a greater extent compared to a plain benzoyl peroxide gel, thus, improving the patients ' compliance (Patel, V.B. et al., 2001).
The problem of strong local irritation experienced by patients using salicylic acid can be overcome through its encapsulation into liposomes (Bhalerao and Raje, 2003), microemulsions and solid lipid nanoparticles. The encapsulation of the salicylic acid into prolonged release systems may be a successful approach for minimization of the side-effects and the application frequency, which would be substantially beneficial to the patients (Woo et al., 2014).

US patent US8758809 B2 refers to a novel advance for treating acne and acne-related symptoms and describes lecithin-type liposomes containing a high concentration of linoleic acid, in which complex of copper and sodium chlorophyllin is encapsulated. The designed liposomes have a diameter ranging in 150-350 $\mathrm{nm}$. According to the description in the patent, the prepared liposomal vesicles are adequate for treatment of seborrheic and acne-prone skin and at the same time, they stimulate the natural regenerative skin processes. Copper is necessary for the formation of the enzyme superoxide dismutase, which reduces oxidative damage associated with inflammatory conditions, such as acne, as well as tissue destruction caused by free radicals generated by ultraviolet light. Formation of copperpeptides, such as the tripeptide complex glycyl-L-histidyl-L-lysine $(\mathrm{GHK})$ - $\mathrm{Cu}$, results in more complete wound healing and reduces scarring resulting from skin pathologies such as acne. Another innovative aspect of this novel approach for treating acne and acne-related symptoms is related with controlled release of the copper, based on anticipated drop in $\mathrm{pH}$ as the liposome enters the skin. $\mathrm{Cu}^{2+}$ ions are loaded into the liposomes in the form of an aqueous solution of sodium-copper-chlorophyllin. The copper can be replaced by two protons; hence, a more acidic $\mathrm{pH}$ favors dissociation of copper from chlorophyllin. The liposome dispersion is formulated at a slightly alkaline $\mathrm{pH}$, typically 7.2-7.6. The copper-chlorophyllin stays intact as long as the liposome stays intact, but is expected to dissociate once the liposome enters the more acidic environment of the skin's outer mantle. The liposomes are dispersed in a dermatologically-acceptable carrier which can contain a skin penetration enhancing agent. In the conducted studies with aqueous gel base containing the dispersion of lecithin liposomes with $0.1 \%$ sodium-copper-chlorophyllin, its effectiveness in treating large pores on the nose and/or cheeks, acne, oiliness of skin, and blotchiness of subjects with mild to moderate acne was evaluated. It was shown that the formulation provides therapeutic benefits for acne and acne-related skin disorders (US patent 8758809 B2, 2014).

The US patent application US20140079761 A1 presents liposomes prepared by phosphatidylcholine and nitric oxide as active ingredient. The prepared liposomes can be incorporated into various semi-solid and liquid forms in order to achieve efficient acne treatment. Namely, according to the research, the incorporation of nitric oxide into the liposomes is supposed to enable a deeper penetration into the skin and a continuous release of the nitric oxide that 
blocks the production of cytokines and interleukin-caused hyperkeratosis. At the same time, the nitric oxide has antioxidant and anti-inflammatory effects which could prevent the cascade that leads to inflammatory skin lesions. Due to the antibacterial effect, the incorporation of this substance into the liposomes would at the same time prevent the excessive colonization of $P$. acnes (US patent 20140079761 A1, 2014).

Studies have shown that povidone-iodine (PVP-iodine) in form of soap solution can be used for topical treatment of mild forms of acne. However, it emerged unambiguously from these studies that the used PVP-iodine soap solution do not provide for a high efficacy of the acne treatment as in almost all cases patients were treated also with antibiotics. An additional drawback of these soap solution is the color patch of the skin may show due to the usual brown color of the solution. The invention presented in US patent application US20120294933 A1 has the aim to provide a well-tolerated, easy applicable pharmaceutical preparation for the topical treatment of acne, which allows lasting, efficient and scar-free treatment also of severe acne forms. Namely, this patent depicts PVP-iodine liposomes for efficient acne treatment due to the antiseptic effects of the active ingredient. The liposomes can be prepared by hydrogenated soy bean lecithin, i.e. Phospholipon ${ }^{\circledR} 90 \mathrm{H}$ or Lipoid S100-3 with a size of $\sim 1 \mu \mathrm{m}$. Satisfactory stability of the vesicles in a period of two years in a wide temperature range is desired, which would make them convenient for incorporation into various pharmaceutical and cosmetic forms (US patent 20120294933 A1, 2014).

A novel composition comprising mucilaginous polysaccharides from Aloe barbadensis, such as aloeride and acemannan, in liposome vesicles that can be used for acne treatment is depicted in patent application CA2700335 A1. The aforementioned Aloe barbadensis metabolites have an antiseptic, hydrating, keratolytic and photoprotective activity. The Aloe barbadensis extract in the composition was in range between 0.5 and $35 \%$ and the liposomes were in range between 0.008 and $8 \%$. This combination has a synergistic activity and reduces the skin inflammation and the pimples associated with acne. Likewise, a reduction in redness of the skin and its structure due to overexposure to UV rays and the external environmental factors that harm the epithelial tissue was seen (CA Patent CA2700335 A1, 2009).

In US patent US5614215 A two different dispersions of lipid vesicles are described, i.e. first dispersion of so-called depth vesicles-liposomes with a great penetrability into the deeper skin layers and second dispersion of surface vesicles-liposomes with properties of retaining for a longer period on the skin surface in order to provide a prolonged release of the incorporated substances. The main lipids constituting the vesicles of the first category (active substance delivered in depth) include at least one linear and saturated fatty chain of length ranging from 16 to 30 carbon atoms, such as hydrogenated phospholipids (from plants or from egg), saturated synthetic phospholipids such as dipalmitoylphosphatidylcholine, or the alkyl ethers or alkyl esters of polyols containing one, two or three fatty chains per molecule. The main lipids constituting the vesicles of the second category (active substance delivered at the surface) are chosen in particular from the group including ionic lipids such as plant- or egg-based natural phospholipids containing unsaturated fatty chains of 16 to 30 carbon atoms, non-ionic lipids such as the alkyl ethers or alkyl esters of polyols containing one or several fatty chains per molecule, including at least one fatty chain of length shorter than 16 carbon atoms, such an lauryl polyglyceryl-6-cetearylglycol ether (US Patent US5614215 A, 1997).

US patent US5034228 A describes liposomes that contain retinoid or a structural analogue of retinoid, as a carotenoid or tretinoin. At the same time, the liposome vesicles can incorporate a complementary active or secondary agent incorporated either in the lipid layer of the liposomes, in which case its amount should not exceed $40 \%$ by weight of the whole lipid phase, or can be incorporated in the water phase, depending on their solubility. Examples of such active substances are erythromycin, clindamycin, metronidazole or other antibiotic or antiseptic agents that enable a combined and efficient acne therapy. The results from the research confirmed the comedolytic activity of the designed vesicles with a concomitantly decreased erythema and hypercanthosis (US patent US5034228 A, 1991).

\section{Niosomes}

Niosomes are second-generation vesicular systems, whose design has helped overcome the disadvantages of conventional liposomes, such as the requirement for vigorous work conditions, limited encapsulation efficacy, instability and expensive production. These structures contain non-ionic surfactants instead of phospholipids, cholesterol which improves the rigidity of the bilayer and water phase and are therefore called non-ionic vesicles (Shilakari et al., 2013; Singh, 2013). In their preparation, different non-ionic surfactants can be used such as polyoxyethylene alkyl ethers and esters, glucosyl dialkyl ethers, polyglycerol alkyl ethers, crown ethers and sorbitan esters (Date et al., 2006).

Niosomes have a series of advantages such as biodegradability, non-toxicity and non-immunogenicity and they are able to encapsulate large amount of materials in a small volume of vesicles (Date et al., 2006; Rajera et al., 2011). As a result of their composition and structure, niosomes improve the properties of stratum corneum by reducing the transepidermal water loss and restore the hydrolipid film (Vyas et al., 2014).

Both niosomes and liposomes behave in a similar manner when releasing the encapsulated drug and they have a similar in vivo behaviour (Kazi et al., 2010). Although niosomes demonstrate a better chemical stability, the physical instability during dispersion may be compared to the 
one of the liposomes. Namely, niosomes, similarly to liposomal vesicles, may undergo the phenomena of aggregation, fusion and leakage of the encapsulated drug (Rahimpour and Hamishehkar, 2012). One of the major concerns is the possibility of hydrolysis of encapsulated drugs, which limits the shelf-life of the niosomal dispersion (Vyas et al., 2014).

Niosomes have been intensively researched in the field of dermatology in order to provide an effective treatment for seborrheic and acne-prone skin. The results have shown that these non-ionic vesicles are capable of penetrating the pilosebaceous units (Madhav and Saini, 2011). Budhiraja and Dhingra (2014) have investigated the potential of niosomes with incorporated rosmarinic acid in acne treatment. The designed niosomal gel has shown greater antimicrobial efficacy to Staphylococcus aureus and Propionibacterium acnes in comparison with the plain gel of rosmarinic acid or the commercial gel with benzoyl peroxide (Budhiraja and Dhingra, 2014). In a study of Gupta et al. (2014), in vitro permeation and retention studies of topical niosomal gel containing a combination of benzoyl peroxide and tretinoin were performed and compared to the permeation and retention of a cream and alcoholic solution containing the same active substances as the niosomal gel. Furthermore, comparative anti-acne activity of the niosomal gel and a cream containing the same combination was evaluated. The results have shown that the drug retention was higher in case of niosomal gel than the cream and alcoholic solution. In vivo studies of the niosomal gel and anti-acne cream of tretinoin and benzoyl peroxide showed that the niosomal gel had greater efficacy than the anti-acne cream with niosomal gels of 4.16-fold lower dose of benzoyl peroxide providing the same therapeutic index at targeted sites in comparison to the anti-acne cream (Gupta et al., 2014). Erythromycin has been also successfully incorporated in a topical niosomal gel, which demonstrated prolonged drug release, increased erythromycin retention and improved skin permeation compared to a plain drug gel and marketed gel (Jigar et al., 2011). The studies of Manconi et al. (2006) showed that by incorporating tretinoin in niosomes, its photodegradation can be reduced. The conducted permeation and retention studies using both tretinoin saturated and non-saturated vesicular formulations showed that alkyl polyglucosides surfactants seem to be an interesting class of amphiphiles for niosome formation because of their ability to improve either transdermal or cutaneous delivery of niosomal tretinoin, depending on their structure. Small, negatively charged niosomal formulations saturated with tretinoin give higher cutaneous retention than both liposomes and commercial topical formulation of tretinoin, indicating that tretinoin cutaneous delivery is strongly affected by the vesicle composition and the thermodynamic activity of the drug (Manconi et al., 2006).

The cosmetic company L'Oreal was the first to patent niosomes as new vesicular systems for pharmaceutic and cosmetic application. In the patent number US4830857, a formulation based on niosomes or a combination of niosomes and liposomes with adequate size was described. The formulation contains water-soluble polyamide polymer having a molecular weight between 1000 and 200.000, at a concentration of 0.01 to $5 \%$ by weight relative to the total weight of the composition. These vesicular systems would represent adequate carriers of active ingredients for treatment of seborrheic and acne-prone skin (US patent 4830857 A, 1989).

A formulation of niosomes, capable of penetrating deeper into the skin layers is presented in the US Patent US5830499 A. These unilamellar vesicles are comprised of non-ionic surfactant, active ingredient and a second hydrophilic surfactant. The non-ionic surfactants could be selected from the group consisting of polyoxyethylene alkyl ethers and esters, sorbitan esters, glucose and sucrose alkyl esters. An ionic surfactant such as sodium laurate and sodium dicetyl phosphate may occasionally be added as a stabilizer. Research results have shown that the designed vesicles are potential carrier systems of active ingredients which could be successfully used in acne treatment (US Patent 5830499 A, 1998).

\section{Microsponges}

In the last ten years porous polymeric systems that enable predictability of the absorption degree of cosmetic/ dermatological active ingredients into the skin have been developed, among which of great significance is the development of microsponges as new system-carriers of active substances (Maiti et al., 2011).

Microsponges are highly cross-linked, porous, polymeric particles which can incorporate a large number of various active components (Patel, A. et al., 2012). Commonly, these systems are made of synthetic polymers and characterized with high degree of cross-linking, thus resulting with particles that are insoluble and stable (Pentewar et al., 2014). The selection of polymers, the method of preparation and the process parameters greatly affect the size and porosity of the microsponges

In cosmetology, microsponges are interesting due to their stability over a wide $\mathrm{pH}$ range and high temperatures, excellent compatibility with a large number of active ingredients and surfaces, as well as high percentage of encapsulation of the active ingredients (Patel, A. et al., 2012). Also, in accordance with the system design, in terms of particle size and size of pores, it is possible to achieve a predictable, controlled release. This property of theirs is especially significant for diminishing the local side-effects upon topical administration of the active ingredients being used in acne treatment (Maiti et al., 2011; Patel, E.K. and Oswal, 2012). Other advantages that the microsponges offer in topical delivery are as follows: improved physical stability and better protection from environmental factors, sustained release of active agent thus prolonging the drug activity, ease of incorporation into a formulated prod- 
uct such as a gel, cream, liquid or powder, improved elegance and aesthetic appeal and reduction of systemic absorption of the topical agents (Patel, A. et al., 2012).

Due to the possibility of sebum absorption, the microsponges are adequate for application in seborrheic and acne-prone skin. The sebostatic effect is ascribed to the spherical particles having potential to retain up to four times more sebum depending on their weight (Kaity et al., 2010). They do not penetrate into the skin layers, but are retained on the surface and enable continuous release of the active ingredient (Maiti et al., 2011). The potential of the microsponges as carriers of active ingredients in acne treatment has been investigated through encapsulation of benzoyl peroxide, erythromycin, tretinoin and other active substances. Results have shown that these carriers provide continuous release of the drug with a concomitant decrease of the skin irritation, which are significant benefits for achievement of effective treatment (Parikh et al., 2009).

Different active substances used in acne treatment such as retinoids, antibiotics and/or keratolytic agents can be combined in topical anti-acne preparation, as was demonstrated in US patent US20090318371 A1, where microsponges with benzoyl peroxide as keratolytic agent were included in the formulation. This formulation is intended to be used for treating moderate to severe acne in the form of a gel or cream comprising retinoid (tazarotene or adapalene), antibiotic (clindamycin phosphate) and/or keratolytic ( $2-5 \%$ of benzoyl peroxide in microsponges) which enables a combined therapy offering less local side-effects. Combining benzoyl peroxide with other active substances in a single pharmaceutical dosage form is oftentimes difficult since benzoyl peroxide is a highly oxidative agent. Thus, in the present invention, its encapsulation in microsponges prevents its reaction with the retinoids and the antibiotic (US Patent US 20090318371 A1, 2009).

\section{Microspheres}

Microspheres are solid spherical particles, ranging $1-1000 \mu \mathrm{m}$ in size, prepared by microencapsulation technique, with inert, natural or synthetic polymers being deposited around solid and liquid micronized particles and the drug being homogeneously dispersed throughout the core (Del Rosso, 2009; Vyas et al., 2014). Specific inert monomers used in the polymerization process for microsphere production are selected depending on their compatibility with the individual active substances. In the case of tretinoin, which degrades in the process of polymerization, microspheres are firstly produced and the active substance is subsequently loaded in the preformed particles (Del Rosso, 2009). In other instances, the active substance can be incorporated into the microsphere during the process of polymerization without the risk of degradation of the drug (Del Rosso, 2009).

When considered as drug carrier systems that are used in dermatology and cosmetology, the microspheres have numerous potential advantages. Namely, they act as a reservoir systems for the active substances, providing sustained drug delivery; so epidermal overload of the active substance is avoided and reduction of cutaneous irritation caused by active substances having concentration-dependent irritation potential could be achieved. Microspheres also show lower potential for transdermal penetration and systemic exposure (Del Rosso, 2009). The delivery of microspheres to the pilosebaceous unit was shown to depend on their mean diameter. Microspheres of $5 \mu \mathrm{m}$ are primarily localized within the pilosebaceous unit, while microspheres larger than $10 \mu \mathrm{m}$ remain on the skin surface and those smaller than $3 \mu \mathrm{m}$ penetrate both the pilosebaceous unit and the epidermis (Webster and Rawlings, 2007). Other advantages of microspheres include: improved skin tolerability due to reduced cutaneous penetration rate of the active substance; most of the commercially available microsphere formulations are easily applied and due to the adequate particle size range of 5 to $50 \mu \mathrm{m}$, they are not palpable on application; just like the microsponges, microspheres are also characterized with a capacity for absorption of the secreted sebum, which makes them convenient and efficient for application on seborrheic and acne-prone skin (Del Rosso, 2009). The active substances which are prone to degradation caused by their chemical reactivity, UV light and other external factors, are protected when encapsulated in the microspheres.

Microspheres have been investigated as carriers for different antiacne drugs. Microspheres with benzoyl peroxide have been shown to significantly reduce the excreted sebum in comparison with a mild liquid cleanser for seborrheic skin (Del Rosso, 2009). In another study, regarding microspheres containing benzoyl peroxide, the efficacy and tolerability of a cream with microspheres and encapsulated benzoyl peroxide (5.5\%) was comparatively examined with a conventional $6 \%$ gel. The blind randomized study lasting for 12 weeks included 48 patients $(>12$ years), with mild to moderate acne. The results showed that the microsphere cream has equivalent or better tolerability than the conventional $6 \%$ gel formulation, as well as greater efficacy and higher patient preference (Smith and Kempers, 2006). A 12-week comparative study of tretinoin gel microsphere $0.1 \%$ and adapalene gel $0.1 \%$ for acne treatment assessed their efficacy and safety. It was shown that both formulations have similar efficacy, with tretinoin gel microsphere resulting in faster onset of action in terms of reduction of comedones compared to the adapalene gel (Nyirady et al., 2001). The combination of benzoyl peroxide formulation and tretinoin formulation in acne treatment may result in oxidation and degradation of tretinoin, due to benzoyl peroxide being strong oxidizing agent and the polyenic chains of tretinoin being prone to oxidation, thereby reducing the effectiveness of tretinoin. However, the encapsulation of tretinoin in microspheres has significantly improved its photostability and incompatibility when combined with erythromycin-benzoyl peroxide gel (Nyiradi et al., 2002) or in presence of erythromycin-benzoyl peroxide

Макед. фарм. билт., 62 (2) 3 - 16 (2016) 
or clindamycin-benzoyl peroxide after exposure to simulated solar UV radiation (Nighland et al., 2006).

In addition to the tendency of the retinoids to degrade upon exposure to factors such as heat, light, oxygen and trace amounts of metal ions, another problem associated with cosmetic and therapeutic formulations of retinoids is their proneness to cause skin irritation. Although the degradation problem can be addressed to some extent by formulating retinoids to include antioxidants and chelating agents, this has been of limited success, particularly in oilin-water emulsions, which are generally the formulations of choice for skin care products. Oil-in-water emulsions appear to facilitate the diffusion of oxygen to the retinoids, thereby lessening the stabilizing effect of the antioxidants. The invention presented in US Patent US5851538 A addresses the need for a retinoid formulation with an aqueous continuous phase which resists decomposition and entails a reduced degree of skin irritation, by formulating the retinoids as particles or particle suspensions in which the particles are porous matrices with the retinoid retained inside the pores. The porous microspheres with encapsulated retinoin present a stable and safe system with a continuous release which would result in greater efficacy and lower skin irritation. The patent describes a stable pharmaceutical composition for topical administration of retinol consisting of an oil-in-water emulsion comprising, suspended in the emulsion, solid water insoluble microscopic particles containing a substantially continuous network of pores open to the exterior of the particles, with the concentration of the retinoid composition relative to the pharmaceutical composition being between about $0.001 \%$ and about $20.0 \%$ by weight. The retinoids are not part of the particle matrix and are typically deposited in the pores by conventional physical means subsequent to the formation of the particles. This composition causes lower irritancy when applied than a composition containing the same concentration of retinol in a non-microscopic particle formulation (US Patent 5851538 A, 1998).

The US patent application US20140271875 A1 describes a formulation of microspheres with isotretinoin in the form of salt, ester or amide. Microspheres are made up of biodegradable polymers such as poly(lactic-co-glycolic acid) (PLGA) ranging from $0.1-10 \mu \mathrm{m}$ in size, with a possibility for a continuous release of the encapsulated active ingredient. Results have shown that this formulation results in improved efficacy and significant decrease of the local side-effects. By employing the compositions and methods of the invention, isotretinoin can be delivered deeply into the hair follicle where it will be converted to the active tretinoin to reach the sebaceous gland (US Patent 20140271875 A1, 2014).

The preparation of microparticles by using naturally occurring polymers with incorporated tretinoin was described in the patent application WO2010023689 A2. Namely, these microparticles are based on ethyl cellulose as a polymer, with a defined particle and pore size in order to achieve controlled release of tretinoin. The particle size of microparticles is also important in terms of spreadability, adhesion and feeling when incorporated in the topical vehicle and applied on the skin. Through variation of the ratio between the polymer and the active substance, a satisfactory encapsulation efficiency and a continuous release can be achieved. It has been shown that when the microparticles are incorporated in a conventional vehicle such as gel, the formulation is found to be non-irritant to the skin and comparable in terms of efficacy in treating acne with a commercially available microparticle preparation (Patent WO2010023689 A2, 2010).

The US Patent application US20100068284 A1 presents a stable topical gel formulation comprising clindamycin and microspheres containing adapalene, wherein the weight ratio of adapalene to the microspheres ranges from about 1:1 to about 1:20. The microspheres are composed of pharmaceutically acceptable polymer, selected from poly(dl-lactic-coglycolic acid), silica, cellulosic polymers, divinylbenzene and methacrylates. The efficacy, safety and tolerability of the stable, fixed dose topical formulation of $0.1 \%$ microsphere adapalene/ $1 \%$ clindamycin gel applied once daily was evaluated vis-a-vis other formulations that are marketed, namely, to that of $0.1 \%$ adapalene and $1 \%$ clindamycin gel, applied once daily; $1 \%$ clindamycin gel, applied twice a day; $0.1 \%$ adapalene gel, applied once daily and $0.1 \%$ microsphere adapalene gel applied once daily, over a period of 12 weeks in patients with acne. It was observed that the formulation described in this patent was more effective on reducing inflammatory and non-inflammatory lesions count when compared against other treatment groups. The group treated with this formulation also exhibited faster onset of action with trend towards reducing lesion count better than all the other groups. This effect points towards a better cumulative effect with microsphere adapalene and clindamycin in the treatment of acne (US Patent 20100068284 A1, 2010).

The patent application WO2010077971 A describes a cosmetic product, dry powder foundation formulations that would be adequate for acne-prone skin. The formulation provides both acne treatment and prevention, as well as sunblock protection. It contains microspheres made up of allyl methacrylate crosspolymer in which salicylic acid is encapsulated, thus helping achieve a continuous release. Furthermore, as anti-acne additives, the formulation includes one or more salicylates, ideally isolated as an extract from willow bark and/or aspen bark. The designed microspheres have incorporated other active substances, such as sulfur, benzoyl peroxide and resorcinol. The incorporation of sunscreens also helps to improve acne, as UV exposure is known to exacerbate the condition (WO Patent App. PCT/US2009/068,298, 2010).

\section{Micro/nanoemulsions}

Microemulsions are transparent dispersions of oil and water, with droplets about $200 \mathrm{~nm}$ in size. They are ther- 
modynamically stable as the result of the interfacial film of molecules of the surfactant and the co-surfactant. The presence of these surface-active substances results in improved penetration through the skin layers. In microemulsions, the active ingredients are dissolved in one of the phases, which is why they are available for immediate release and action (Grampurohit et al., 2011; Shalita et al., 2004).

It is considered that in local application of microemulsions, there are interactions with stratum corneum, when the structural organization of the layers of lipids is changed and the potential for penetration is increased (Badawi et al., 2009). The microemulsions have been shown to be a suitable vehicle for topical application of several active substances used in acne treatment, such as azelaic acid, retinoic acid, tretinoin and salicylic acid. The incorporation of azelaic acid in a viscosized microemulsion resulted in a significantly greater permeation in comparison with a commercial gel of this active ingredient, which led to a conclusion that the designed system of microemulsions with azelaic acid would be adequate for an efficient acne treatment (Gasco et al., 1991). In other study, prepared lecithinised microemulsions were proven as promising colloidal carriers allowing higher skin permeation and retentability of tretinoin compared to a solution, gel and marketed preparations containing this active substance (Surabhi et al., 2010). Microemulsions with erythromycin and microemulsion-based gels can be considered as a suitable substitute for commercial erythromycin gel containing high amount of alcohol. It was shown that this erythromycin microemulsion-based gel is non-irritant and it is active against the tested microorganisms (Date et al., 2006).

Nanoemulsions are defined as dispersions (oil dispersed in water or water dispersed in oil) with very small droplets, sized in the range $20-200 \mathrm{~nm}$, typically below 100 $\mathrm{nm}$. They have a large surface area and offer an opportunity for dissolving a large number of active substances. Nanoemulsions can be used as carriers for both hydrophilic and lipophilic active substances and they also positively influence the skin hydration and the viscoelasticity (Antonio J.R. et al., 2014). Due to their composition, size and the other properties, nanoemulsions show a significantly larger penetrability and skin retention, in comparison with the other colloidal systems, such as micro/nanoparticles, liposomes, microemulsions etc. (Singh, M. and Jain, 2011).

Micro/nanoemulsions are especially convenient systems in cosmetics because they show significant stability, do not sediment and do not flocculate. Another advantage is their small size, which provides a large surface area and a possibility for controlled release. The research shows that nanoemulsions selectively target the pilosebaceous unit and laterally penetrate the surrounding tissue. Furthermore, the droplets may be fused into the bacterial membrane (due to the present surfactants) which leads to its lysis (Prasad et al., 2012).

One prospective, randomized, open label, active-controlled, multicentric, post-marketing clinical study assessed the efficacy and safety of the therapy with nanoemulsion gel formulation of adapalene $0.1 \%$ and clindamycin $1 \%$ combination and compared it with a conventional gel formulation in Indian patients with face acne. The novel formulation was demonstrated to significantly better reduce the total, inflammatory and noninflammatory acne lesions as compared to the conventional gel. With the nanoemulsion gel, significantly lower incidence and lesser intensity of adverse events like local irritation and erythema were recorded. Therefore, it can be concluded that adapalene and clindamycin combination nanoemulsion gel produces better therapeutic response and shows better safety profile compared to the conventional formulations (Prasad et al., 2012). This nanoemulsion gel formulation of adapalene and clindamycin combination has been patented and described in patent application WO 2012053010 A2. In addition, there are several other patented formulas regarding innovations in the design of micro/nanoemulsions as carriers for active substances in acne treatment.

The US Patent US8268367 B2 describes a nanoemulsion-based formulation which comprises a combination of antibacterial ingredients, lemon juice and/or rose water as therapeutically active aqueous phase entrapped in oil phase from selected essential oils. The formulation comprises nonionic surfactants Tween 20 and Tween 80 (88:12), ethanol as co-surfactant and lanolin and stearic acid as softening agents. The designed water-in-oil nanoemulsion has droplets ranging 0.5 to $50 \mathrm{~nm}$ in size and it is adequate for topical acne treatment and other skin disorders like eczema, psoriasis etc. as a result of improved penetration and localization in the skin and the excellent thermodynamic stability of the system, as well as low skin irritation and reservoir effect that promotes drug localization in the skin enabling controlled delivery of the therapeutic agents (US Patent US8268367 B2, 2012).

US patent application US2010/0226983 A1 describes a nanoemulsion formulation comprising oil and water phase and two surfactants which can incorporate various active substances for efficient acne treatment. The size of the nanoemulsion droplets is $\sim 150 \mathrm{~nm}$ in order to achieve effective penetration into the pilosebaceous unit and a high local concentration of the active ingredient (US20100226983 A1, 2010).

In US Patent US5753241 A, an oil-in-water nanoemulsion having oil globules with a mean size of less than 100 $\mathrm{nm}$ has been presented. The nanoemulsion comprises amphiphilic lipid component characterized in that it comprises at least one non-ionic amphiphilic lipid component which is liquid at temperatures lower than $45^{\circ} \mathrm{C}$, wherein the ratio by weight of the amount of oil to the amount of amphiphilic lipid component is from 2 to 10 . The amphiphilic lipid component additionally contains one or more ionic amphiphilic compounds preferably chosen from the group of neutralized anionic lipids, amphoteric ionic lipids or alkylsulfonic derivatives. The nanoemulsion further comprises and additive that improves transparency (low- 
er alcohol or glycol). It can incorporate water-soluble or liposoluble dermatological and cosmetic ingredients. Due to the presence of water as exterior phase, this system is especially convenient for treatment of seborrheic skin (US Patent US5753241 A, 1998).

\section{Lipid nanoparticles (SLNs and NLCs)}

Lipid nanoparticulated systems (solid lipid nanoparticles-SLNs and nanostructured lipid carriers-NLCs) are based on a lipid component (triglycerides, glycerides or solid wax at room temperature) which, when melted or in liquid state forms nanostructures while cooling down during the emulsion process. The interest for these systems is based on the absence of organic solvents which are usually used in the formation of the other colloidal systems (AtruxTallau et al., 2010).

Solid lipid nanoparticles (SLNs) are submicron-sized colloidal systems ranging from 50 to $1000 \mathrm{~nm}$ in size, comprising lipids (highly purified triglycerides, complex mixtures of glycerides and waxes) dispersed in a water solution of surfactant in order to achieve a physical stability of the dispersion (Müller et al., 2000). The usually utilized surfactants are poloxamer 188 , polysorbate 80 , lecithin, tyloxapol, polyglycerol methylglucose distearate, sodium cocoamphoacetate and saccharose fatty acid esters (Schäfer-Korting and Mehnert, 2005). SLNs are suitable for incorporation of lipophilic, hydrophilic and poorly water-soluble drugs within the lipid matrix in considerable amounts (Date et al., 2006). Due to utilization of physiologically acceptable lipids, SLNs show improved body/tissue tolerance. Other advantages that these colloidal carriers show are as follows: protection of labile compounds from chemical degradation, e.g. for retinol, coenzyme Q-10, tocopherol (Jenning and Gohla, 2001; Schäfer-Korting et al., 2007); depending on the produced SLN type, modulation of drug release profile is possible (Date et al., 2006). SLNs having a drug-enriched shell are suitable for incorporation of active substances that are released as a burst, whereas SLNs with a drug-enriched core show sustained drug release (Date et al., 2006). SLNs may alleviate skin dryness caused by many anti-acne agents, due to an occlusive effect. Moreover, SLNs have the ability to reflect and scatter UV radiation, thus act as physical sunscreens on their own and allow improved protection of photolabile drugs/antiacne agents (Date et al., 2006; Wissing and Müller, 2001).

A major drawback of SLNs is the low capacity of incorporation of the hydrophilic active substances, which limits their use. Namely, only the highly potent hydrophilic ingredients, which are efficient in small doses, would be adequate for incorporation into the lipid matrix. Among the other disadvantages of these systems are the appearance of agglomeration of particles, an unpredictable tendency towards gel-formation, drug expulsion and unexpected dynamics of polymer transitions that significantly influence the stability and the shelf-life of these formulations (Patil et al., 2013; Thassu et al., 2007; Vyas et al, 2014)

SLNs are the first generation of lipid nanoparticles that were later replaced by NLCs, as a newer generation of lipid systems with numerous advantages. The main difference between SLNs and NLCs is the composition and the physical state of the lipids. In the case of SLNs, the core is composed of a solid lipid, whereas NLCs have a liquid lipid core (Pathak and Thassu, 2009). SLNs prepared from one highly purified lipid can crystallize in a perfect crystalline lattice that allows smaller space for drug incorporation (Yoon, G. et al., 2013). The spatially different lipids used in preparation of NLCs, however, do not form a perfect crystalline lattice structure and the imperfections in the solid matrix of NLCs allow for incorporation of drugs in molecular form or as amorphous clusters (Saupe et al., 2005; Yoon, G. et al., 2013). These imperfections in NLCs enable their higher drug loading capacity and prevention of drug expulsion (Yoon $\mathrm{G}$ et al., 2013). At the same time, the solubility of lipophilic drugs being higher in liquid lipids than in solid lipids and the possibility of modulation of drug release represent the main advantages of NLCs over SLNs (Vyas et al., 2014; Yoon, G. et al., 2013).

Recent research in the field of potential application of lipid nanoparticles in acne treatment shows that they are superior to nanoemulsions and the other nanoparticulated systems. SLNs have been investigated as potential carriers of: tretinoin, isotretinoin, retinoic acid, sphingosomes, cyproterone acetate and triclosan (Vyas et al., 2014). The results pointed out that these lipid carriers enable decreased skin irritation and greater tolerance, occlusiveness, slower release of the incorporated active substances, increased permeability into the skin layers and greater stability (Vyas et al., 2014). Lipid nanocarriers have also been investigated for combined acne therapy. The incorporation of tretinoin and tetracycline into negatively-charged NLCs ranging $200 \mathrm{~nm}$ in size resulted in a significantly greater antibacterial activity towards Staphylococcus aureus in comparison with the control solution (Lin et al., 2013).

A delivery system based on lipid nanoparticles is described in the patent application WO 2011116963 A2. The formulation relates to lipid nanoparticles constituted by a solid lipid matrix at room temperature, or by a matrix formed by a mixture of liquid (oils) and solid lipids at room temperature which are coated with a polymer and can incorporate different active substances, such as those used in acne treatment. The delivery system of this invention avoids the diffusion of hydrophilic active substances in the SLN and NLC dispersions, enables greater stabilization of the incorporated active substance than in the SLNs and the NLCs, and has a greater epidermal penetration capacity than other known delivery systems (WO Patent App. PCT/ EP2011/001,475)

The patent application WO2009111852 A2 presents a formulation of SLNs with retinoids and lipophilic amines. Through formation of ionic pairs between retinoic acid and the lipophilic amines, such as stearylamine, high encapsu- 
lation efficacy of retinoic acid is achieved and an opportunity for its prolonged release exists. Skin irritation studies showed that the SLNs loaded with the ion pairing were significantly less irritating when compared to the marketed retinoic acid cream. This novel SLNs formulation represents a promising alternative for topical treatment of acne with retinoic acid (Castro et al., 2009; WO Patent App. PCT/BR2009/000,072).

\section{Conclusion}

The use of various systems as carriers of active substances is becoming more popular in modern cosmetology, due to the need for formulation of efficient, safe and acceptable cosmetic products. One of the recent focuses of research in the field of acne treatment has been the assessment of different novel drug delivery systems as carriers for anti-acne drugs. In the last two decades, there has been a significant increase in the number of patents in cosmetology, with many patents emerging in the area of acne treatment and some of these patented formulations becoming commercially available. The novel drug delivery systems can help overcome the limitations of conventional formulations used in acne treatment, offering several advantages such as possibility for controlled release of the active substances, improved stability and reduction of side-effects, therefore, improving the patients' compliance to the treatment.

\section{References}

Antonio, J.R., Antônio, C.R., Cardeal, I.L.S., Ballavenuto, J.M.A., Oliveira, J.R., 2014. Nanotechnology in dermatology. An. Bras. Dermatol. 89(1), 126-136.

Atrux-Tallau, N., Denis, A., Padois, K., Bertholle, V., Huynh, T.T.N., Haftek, M., Falson, F., Pirot, F., 2010. Skin absorption modulation: innovative non-hazardous technologies for topical formulations. Open Dermatol. J. 4, 3-9.

Ayala, F.A., 2009. Topical antiacne preparations containing retinoid (tazarotene or adapalene), antibiotic (clindamycin phosphate) and/or keratolytic (microsponged benzoyl peroxide). US Patent No. US 20090318371 A1.

Badawi, A.A., Nour, S.A., Sakran, W.S., El-Mancy, S.M.S., 2009. Preparation and evaluation of microemulsion systems containing salicylic acid. AAPS PharmSciTech, 10(4), 10811084.

Bergler-Czop, B., 2014. The aetiopathogenesis of acne vulgaris what's new? Int. J. Cosmet. Sci. 36(3), 187-194.

Bhalerao, S.S., Raje Harshal, A., 2003. Preparation, optimization, characterization, and stability studies of salicylic acid liposomes. Drug Dev. Ind. Pharm. 29(4), 451-467.

Bhowmick, S.B., Panigrahi, L., Dolai, S.K., 2010. Microparticles, WO Patent App. PCT/IN2009/000,469.

Bouwstra, J.A. 1998. Phospholipid-and cholestrol-free aqueous composition for topical application to the skin. US Patent 5830499 A.

Brenner, S., 2013. The clinical nanomedicine handbook. CRC Press, Boca Raton, pp. 92-95.
Brisaert, M., Gabriëls, M., Matthijs, V., Plaizier-Vercammen, J., 2001. Liposomes with tretinoin: a physical and chemical evaluation. J. Pharm. Biomed. Anal. 26(5-6), 909-917.

Budhiraja, A., Dhingra, G., 2014. Development and characterization of a novel antiacne niosomal gel of rosmarinic acid. Drug Deliv. 22(6), 723-730.

Castro, G,A., Coelho, A.L., Oliveira, C.A., Mahecha, G.A., Oréfice, R.L., Ferreira, L.A., 2009. Formation of ion pairing as an alternative to improve encapsulation and stability and to reduce skin irritation of retinoic acid loaded in solid lipid nanoparticles. Int. J. Pharm. 381(1), 77-83.

Chaudhary, M.,Naithani, V., 2012. Topical herbal formulation for treatment of acne and skin disorders. US Patent No. 8268367 B2.

Cid, V.R.F., Andrade, B.E.E.R., Sandoval, T.D.P., 2009. Composition comprising mucilaginous polysaccharides derived from aloe barbadensis combined with liposomes, method for obtaining same and use thereof as a sun protector, an anti-acne agent, an epidermal regenerator and a moisturiser. CA Patent App. CA 2700335 A1.

Colipa, the European Cosmetics Association, 2010. Science, beauty and care: innovating for a sustainable future. Activity Report. Available from: https://www.cosmeticseurope.eu/ files/8414/6407/3682/CE_Activity_Report_2010.pdf

Das, S., Reynolds, R.V., 2014. Recent advances in acne pathogenesis: implications for therapy. Am. J. Clin. Dermatol. 15(6), 479-488.

Date, A.A., Naik, B. Nagarsenker, M.S., 2006. Novel drug delivery systems: potential in improving topical delivery of antiacne agents. Skin Pharmacol. Physiol. 19(1), 2-16.

Degitz, K., Placzek, M, Borelli, C., Plewig, G., 2007. Pathophysiology of acne. J. Dtsch. Dermatol. Ges. 5(4), 316323.

Del Rosso, J. Q. (Ed.). (2009). Benzoyl Peroxide Microsphere Formulations: What is the Science Supporting Microsphere Vehicle Technology and Clinical Use? J. Clin. Aesthet. Dermatol. 2(9), 46-54.

De Medeiros-Ribeiro, Costa Almeida, L.M., B., Costa, A., Francesconi, F., Follador, I., Rocio Neves, J., 2015. Etiopathogeny of acne vulgaris: a practical review for dayto-day dermatologic practice. Surg. Cosmet. Dermatol. 7(3), 20-26.

Dhuppad, U.R., Bhamre, N.B., Chaudhari, S.S., Trivedi, G., Sharma, A.D., Dongre, P., 2010. Stable fixed dose topical formulation, US Patent No. US20100068284 A1.

Donello, J.E., Yang, R., 2014. Compositions including encapsulated isotretinoin and methods for use thereof. US Patent No. US 20140271875 A1.

Dorogi, R.L., Vasily D.B., McCook, J,P., 2014. Skin treatment compositions containing copper-pigment complexes. US Patent No. US 8758809 B2.

Egbaria, K., Weiner, N., 1990. Liposomes as a topical drug delivery system. Adv. Drug Deliv. Rev. 5(3), 287-300.

Fluhr, J.W., Barsom, O., Gehring, W., Gloor, M., 1999. Antibacterial efficacy of benzoyl peroxide in phospholipid liposomes. Dermatology, 198(3), 273-277.

Froix, M., Pukshansky, M., Nacht, S., 1998. Retinoid formulations in porous microspheres for reduced irritation and enhanced stability, US Patent No. US 5851538 A.

Gasco, M.R., Gallarate, M., Pattarino, F., 1991. In vitro permeation of azelaic acid from viscosized microemulsions. Int. J. Pharm. 69(3), 193-196. 
Goulden, V., Clarck, S., Cunliffe, W., 1997. Post-adolescent acne: a review of clinical features. Br. J. Dermatol. 136(1), 66-70.

Grampurohit, N., Ravikumar, P., Mallya, R., 2011. Microemulsions for topical use-a review. Ind. J. Pharm. Edu. Res. 45(1), 100107.

Gupta, A., Singh, S., Kotla, N.G., Webster, T.J., 2014. Formulation and evaluation of a topical niosomal gel containing a combination of benzoyl peroxide and tretinoin for antiacne activity. Int. J. Nanomedicine 24(10), 171-182.

Handjani, R.M., Ribier, A, Vanlerberghe, G., Zabotto, A., Griat, J., 1989. Cosmetic and pharmaceutical compositions containing niosomes and a water-soluble polyamide, and a process for preparing these compositions. US Patent No. US $4830857 \mathrm{~A}$.

Harhoff, D., Hall, B.H., 2002. Intellectual property strategy in the global cosmetics industry. Ludwig-Maximilians Universitaet and UC Berkeley.

Jenning, V., Gohla, S.H., 2001. Encapsulation of retinoids in solid lipid nanoparticles (SLN). Journal of microencapsulation, 18(2), 149-158.

Jigar, V., Puja, V., Krutika, S., 2011. Formulation and evaluation of topical niosomal gel of erythromycin. Int. J. Pharm. Pharm. Sci. 3(1), 123-126.

Kaity, S., Maiti, S., Ghosh, A. K., Pal, D., Ghosh, A., Banerjee, S., 2010. Microsponges: A novel strategy for drug delivery system. J. Adv. Pharm. Technol. Res. 1(3), 283-290.

Kazi, K.M., Mandal, A.S., Biswas, N., Guha, A., Chatterjee, S., Behera, M., Kuotsu, K., 2010. Niosome: a future of targeted drug delivery systems. J. Adv. Pharm. Technol. Res. 1(4), 374-380.

Knor, T., 2005. The pathogenesis of acne. Acta Dermatovenerol. Croat. 13(1), 44-49.

Lamprecht, A., 2009. Nanotherapeutics: drug delivery concepts in nanoscience. Pan Stanford Pub., Singapore, pp.141-142.

Leeuw, J. D., Vijlder, H. D., Bjerring, P., Neumann, H., 2009. Liposomes in dermatology today. J. Eur. Acad. Dermatol. Venereol. 23(5), 505-516.

Lin, C.H., Fang, Y.P., Al-Suwayeh, S.A., Yang, S.Y., Fang, J.Y., 2013. Percutaneous absorption and antibacterial activities of lipid nanocarriers loaded with dual drugs for acne treatment. Biol. Pharm. Bull. 36(2), 276-286.

Madhav, N.V.S., Saini, A., 2011. Niosomes: a novel drug delivery system. Int. J. Res. Pharm. Chem. 1(3), 498-511.

Maiti, S., Kaity, S., Ray, S., Sa, B., 2011. Development and Evaluation of Xanthan Gum-Facilitated Ethyl Cellulose Microsponges for Controlled Percutaneous Delivery of Diclofenac Sodium. Acta Pharm. 61(3), 257-270.

Malaekeh-Nikouei, B., Golmohammadzadeh, Sh., Hosseini, M., Nassirli, H., 2011. Preparation and characterization of liposomes encapsulated with clindamycin and tretinoin. Pharmacie Globale (IJCP), 2(6), 1-4

Maloney, J.D., Barger, K.N., 2010. Acne treatment powder foundation, WO Patent App. PCT/US2009/068, 298.

Manconi, M., Sinico, C., Valenti, D., Lai, F., Fadda A.M. 2006. Niosomes as Carriers for Tretinoin. III. A Study Into the in Vitro Cutaneous Delivery of Vesicle-Incorporated Tretinoin. Int. J. Pharm. 311(1-2), 11-19.

Meybeck, A., Michelon, P., Montastier, C., Redziniak, G., 1991. Pharmaceutical composition, in particular dermatological or cosmetic, comprising hydrous lipidic lamellar phases or liposomes containing a retinoid or a structural analogue thereof such as a carotenoid. US Patent No. US 5034228
Miranda, F.L.A., Assis, C.G.G., Lambert, O.R., Tadeu, L.B.V., Aprecida, D.O.C., Bohorquez, M.G.A., 2009. Process to obtain a pharmaceutical composition of retinoids, derivative product of retinoids and its use. WO Patent App. PCT/ BR2009/000,072.

Moradi Tuchayi, S., Makrantonaki, E., Ganceviciene, R., Dessinioti, C., Feldman, S.R., Zouboulis, C.C., 2015. Acne vulgaris. Nat. Rev. Dis. Primers 1, 15029.

Müller, R.H., Mäder, K., Gohla, S., 2000. Solid lipid nanoparticles (SLN) for controlled drug delivery-a review of the state of the art. Eur. J. Pharm. Biopharm. 50(1), 161-177.

Nighland, M., Yusuf, M., Wisniewski, S., Huddleston, K., Nyirady, J., 2006. The effect of simulated solar UV irradiation on tretinoin in tretinoin gel microsphere $0.1 \%$ and tretinoin gel $0.025 \%$. Cutis 77(5), 313-316.

Nyirady J, Camelle L, Yusuf M, Migone P, Wisniewski S., 2002. The stability of tretinoin in tretinion gel microsphere $0.1 \%$. Cutis 70(5), 295-298.

Nyirady, J., Grossman, R.M., Nighland, M., Berger, R.S., Jorizzo, J.L., Kim, Y.H., Martin, A.G., Pandya, A.G., Schulz, K.K., Strauss, J.S., 2001. A comparative trial of two retinoids commonly used in the treatment of acne vulgaris. J. Dermatolog. Treat. 12(3), 149-157.

OECD. 2004. Patents and innovation: trends and policy challenges, OECD Publishing, Paris. http://dx.doi. org/10.1787/9789264026728-en

Parikh, B.N., Gothi, G.D., Patel, T.D., Chavda, H.V., Patel. C.N., 2009. Microsponge as novel topical drug delivery system. Journal of Global Pharma Technology 2(1), 17-29.

Patel, A., Updhyay, P., Trivedi, J., Shah, S., Patel, J., 2012. Microsponge as versatile tool for topical route: a review. Int. J. Pharm. Sci. Res. 3(9), 2926-2937.

Patel, E.K., Oswal, R.J., 2012. Nanosponge and micro sponges: A novel drug delivery system. Int. J. Res. Pharm. Chem. 2(2), 237-244.

Patel, V.B., Misra, A.N., Marfatia, Y.S., 2001. Preparation and comparative clinical evaluation of liposomal gel of benzoyl peroxide for acne. Drug Dev. Ind. Pharm. 27(8), 863-870.

Pathak, Y., Thassu, D., 2009. Drug delivery nanoparticles formulation and characterization. Informa Healtcare USA, New York.

Patil, J., Gurav, P., Kulkarni, R., Jadhav, S., Mandave, S., Shete, M., Chipade, V., 2013. Applications of Solid Lipid Nanoparticle in Novel Drug Delivery System. Br. Med. Bull. 1(2), 103-118.

Paye, M., Barel, A.O., Maibach, H.I., 2005. Handbook of cosmetic science and technology, second ed. CRC Press, Boca Raton.

Pentewar, R.S., Kazi, S., Bharti, R., Pulgamwar, G., 2014. MDS Technology: An Approach for Topical, Oral Controlled and Cosmetic Formulations. Res. J. Pharm. Biol. Chem. Sci. 5(3), 1170-1190.

Perricone, N.V., 2014. Systems and methods for treatment of acne vulgaris and other conditions with a topical nitric oxide delivery system. US Patent No. US20140079761 A1.

Reimer, K., Fleischer, W., Hopp, M., 2012. Use of PVP-Iodine Liposomes for Treatment of Acne. US Patent No. US 20120294933 A1.

Prasad, S., Mukhopadhyay, A., Kubavat, A., Kelkar, A., Modi, A., Swarnkar, B., Bajaj, B., Vedamurthy, M., Sheikh, S., Mittal, R., 2012. Efficacy and safety of a nano-emulsion gel formulation of adapalene $0.1 \%$ and clindamycin $1 \%$ combination in acne vulgaris: a randomized, open label, 
active-controlled, multicentric, phase IV clinical trial. Indian. J. Dermatol. Venereol. Leprol. 78(4), 459-467.

Rahimpour, Y., Hamishehkar, H., 2012. Niosomes as carrier in dermal drug delivery, Recent advances in novel drug carrier systems, PhD. Ali Demir Sezer (Ed.), InTech, DOI: 10.5772/51729. Available from: https:/www.intechopen. com/books/recent-advances-in-novel-drug-carrier-systems/ niosomes-as-carrier-in-dermal-drug-delivery.

Rajera, R., Nagpal, K., Singh, S.K., Mishra, D.N., 2011. Niosomes: a controlled and novel drug delivery system. Biol. Pharm. Bull. 34(7), 945-953.

Ramos-e-Silva, M., Carneiro, S.C., 2009. Acne vulgaris: review and guidelines. Dermatol. Nurs. 21(2), 63-68.

Ribier, A., Simonnet, J. T., 1997. Cosmetic composition for the simultaneous treatment of the surface and deep layers of the skin, its use. US Patent No. US 5614215 A.

Ribier, A., Simonnet, J.T., Legret, S., 1998. Transparent nanoemulsion less than $100 \mathrm{~nm}$ based on fluid nonionic amphiphilic lipids and use in cosmetic or in dermopharmaceuticals. US Patent No. 5753241 A.

Rosen, M.R., 2005. Delivery system handbook for personal care and cosmetic products: technology, applications, and formulations. William Andrew Pub., Norwich, New York, pp. 101-118.

Saupe, A., Wissing, S., Lenk. A., Schmidt, C., Müller, R. 2005. Solid lipid nanoparticles (SLN) and nanostructured lipid carriers (NLC)-structural investigations on two different carrier systems. Bio-Med Mater Eng. 15(5), 393-402.

Schäfer-Korting, M., Mehnert, W., 2005. Delivery of lipophilic compounds with lipid nanoparticles-applications in dermatics and for transdermal therapy. Lipospheres in Drug Targets and Delivery. Approaches, Methods and Applications, Nastruzzi, C.(Ed.). CRC Press, Boca Raton, pp.129-130.

Schäfer-Korting, M., Mehnert, W., Korting, H.C., 2007. Lipid nanoparticles for improved topical application of drugs for skin diseases. Adv. Drug Deliv. Rev. 59(6), 427-443.

Schäfer-Korting, M., Korting, H.C., Ponce-Pöschl, E., 1994. Liposomal tretinoin for uncomplicated acne vulgaris. Clin. Investig. 72(12), 1086-1091.

Schramlová, J. , Blazek, K., Bartácková, M., Otová, B., Mardesicová, L., Zizkovský, V., Hulínská, D., 1997. Electron microscopic demonstration of the penetration of liposomes through skin. Folia Biol. (Praha) 43, 165-169.

Shalita, A.R., Berson, D.S., Thiboutot, D.M., Leyden, J.J., Parizadeh, D., Sefton, J., Walker, P.S., Gibson, J.R., Tazarotene Cream in Acne Clinical Study Investigator Group, 2004. Effects of tazarotene $0.1 \%$ cream in the treatment of facial acnevulgaris: Pooled results from two multicenter, double-blind, randomized, vehicle-controlled, parallel-group trials. Clinical therapeutics 26(11), 18651873.

Shilakari, G., Singh, D., Asthana, A., 2013. Novel vesicular carriers for topical drug delivery and their application. J. Eur. Acad. Dermatol. Venereol. 21(1), 77-86.

Singh, M., Jain, S., 2011. Nanoemulsions for Skin Targeting: Present Status and Future Prospects. Drug Delivery Letters 1(2), 159-170.
Singh, S., 2013. Niosomes: A role in targeted drug delivery system. Int. J. Pharm. Sci. Res. 4(2), 550-557.

Sinha, P., Srivastava, S., Mishra, N., Yadav, N.P., 2014. New perspectives on antiacne plant drugs: contribution to modern therapeutics.. BioMed Res. Int., Article ID 301304. vol. 201, 1-19. http://dx.doi.org/10.1155/2014/301304.

Smith ,S.R., Kempers, S., 2006. A study of 5.5\% benzoyl peroxide microsphere cream versus $6 \%$ benzoyl peroxide gel in the treatment of acne vulgaris. Cosmet Dermatol. 19, 537-542.

Surabhi, K., Katare, O.P., Sushma, D., 2010. Lecithinised microemulsions for topical delivery of Tretinoin. Int. J. Drug Dev. Res. 2(4), 711-719.

Sutcliffe, J.A., Ciotti, S.M., Baker, J.R., 2010. Compositions for treatment and prevention of acne, methods of making the compositions, and methods of use thereof. US20100226983 A1.

Taglietti, M., Hawkins, C.N., Rao, J., 2008. Novel topical drug delivery systems and their potential use in acne vulgaris. Skin Therapy Lett. 13(5), 6-8.

Thassu, D., Pathak, Y., Deleers, M., 2007. Nanoparticulate DrugDelivery Systems, in:Thassu, D., Deleers, M., Pathak, Y. (Eds.), Nanoparticulate drug delivery systems. CRC Press Taylor and Francis Group, Boca Raton, pp. 6-7.

Toll, R., Jacobi, U., Richter, H., Lademann, J., Schaefer, H., Blume-Peytavi, U., 2004. Penetration profile of microspheres in follicular targeting of terminal hair follicles. J. Invest. Dermatol. 123(1), 168-176.

Union for Ethical Biotrade. 2010. A review of patent activity in the cosmetics sector in the context of the ethical sourcing of biodiversity Information Note 1 of 4 Trends in patent activity in the cosmetics and perfume sectors.

Viladot, P.J.L.L., Delgado, G.R., Fernandez, B.A., 2011. Lipid nanoparticle capsules. WO Patent App. PCT/ EP2011/001,475.

Vyas, A., Kumar Sonker, A., Gidwani, B., 2014. Carrier-based drug delivery system for treatment of acne. The Scientific World J, 2014.

Webster, G.F., Rawlings, A.V., 2007. Acne and its therapy. CRC Press Taylor and Francis Group, Boca Raton.

Wissing, S.A., Müller, R.H., 2001. Solid lipid nanoparticles (SLN)-a novel carrier for UV blockers. Die Pharmazie 56(10),783-786.

Woo, J.O., Misran, M., Lee, P.F., Tan, L.P., 2014. Development of a controlled release of salicylic acid loaded stearic acid-oleic acid nanoparticles in cream for topical delivery. Scientific World J. Article ID 205703, 1-7. doi:10.1155/2014/205703.

Yoon, G., Park, J.W., Yoon, I.S., 2013. Solid lipid nanoparticles (SLNs) and nanostructured lipid carriers (NLCs): recent advances in drug delivery. Journal of Pharmaceutical Investigation 43(5), 353-362.

Zakir, F., Vaidya, B., Goyal, A.K., Malik, B., Vyas, S.P., 2010. Development and characterization of oleic acid vesicles for the topical delivery of fluconazole. Drug Deliv. 17(4), 238248.

Zouboulis, C. C., 2014. Acne vulgaris. Hautarzt 65(8), 733-747. 


\title{
Резиме
}

\section{Нови приоди во третманот на Acne vulgaris: Патенти поврзани со микро/нанопартикулирани системи}

\author{
Надица Сибиновска' ${ }^{1}$ Венера Комониㄹ, Катерина Анчевска Нетковска',

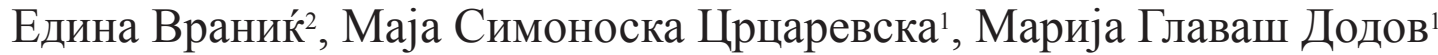

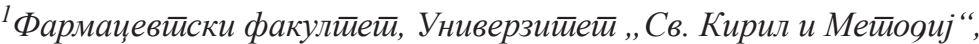 \\ Мајка Тереза 47, 1000 Скойје, Макеоонија \\ ${ }^{2}$ Ояgел за фармацевйска йехнолоіија, Фармацевйски факулйей, Универзийей во Сараево, \\ Змај оо Босна 8, 71000 Сараево, Босна и Хериееіовина
}

Клучни зборови: микропартикулирани ситеми, нанопартикулирани системи, Acne vulgaris, патенти

Acne vulgaris (акне) е хронична инфламаторна дерматоза која влијае на пилосебацеалната единица, со разнолична клиничка слика која вклучува инфламаторни и неинфламаторни кутани лезии. Оваа мултифакторијална болест најчесто се јавува кај адолесценти, но сепак може да ги погоди и децата и возрасните.

Постојат различни терапевтски опции за третман на акни и опфаќаат топикални, системски или хормонални агенси или нивни комбинации. Изборот на терапија зависи од неколку фактори, како што се тежината и степенот на болеста и зафатеното место. Често користена топикална терапија на акни вклучува бензоил пероксид, салицилна киселина, антибиотици, ретиноиди, азелаична киселина, сулфонски агенси и нивни комбинации. Системските антибиотици се индицирани за употреба при умерени до тешки инфламаторни акни и треба да се користат во комбинација со топикален ретиноид и бензоил пероксид.

Достапните конвенционални формулации често предизвикуваат несакани ефекти, меѓу кои кожна иритација, сувост, лупење, чешање, што води до намалено придржување на пациентот кон терапијата и нарушена терапевтска ефикасност.

Новите системи за насочување на активни супстанции се ветувачка опција за подобрување на резултатот од третманот на акни, бидејќи може да ги намалат несаканите ефекти предизвикани од терапевтските агенси или да ги променат нивните својства, истовремено нудејќ можност за модифицирано ослободување и подобрена кожна пенетрација на активните супстанции.

Производителите на козметика применуваат микро/нанотехнологија во нивните формулации, а патентната заштита на козметичките производи добива сѐ поголемо значење во изминатите децении.

Овој труд дава преглед на микро/нанопартикулираните системи кои може да се користат во третман на акни, како и на објавените патенти кои се однесуваат на нив. 